\title{
CURRÍCULO E MATERIAIS DIDÁTICOS PARA A EDUCAÇÃO ESCOLAR INDÍGENA NO BRASIL
}

\author{
Curriculum and teaching materials for the indigenous school education in Brazil
}

Plan de estudios y materiales didácticos para la educación escolar indígena en Brasil

Marta Coelho Castro Troquez*

\begin{abstract}
Resumo
Este artigo procura analisar a proposta de produção de livros e materiais didáticos do Referencial Curricular Nacional para a Educação Escolar Indígena publicado pelo MEC em 1998. A pesquisa é desenvolvida a partir de estudos do campo do currículo e de procedimentos metodológicos da análise documental. Para tal, são analisadas, sobretudo, as falas dos professores indígenas registradas no Referencial, tomado como principal documento de análise. Os resultados mostram que os livros didáticos e materiais didáticos propostos à época privilegiaram a sistematização de saberes próprios/indígenas, que é uma das condições da escola indígena. Contudo, há um desafio a ser superado, que é a elaboração e a publicação de livros e materiais didáticos diferenciados e interculturais em que os conhecimentos indígenas e os conhecimentos escolares não indígenas sejam contemplados.
\end{abstract}

PALAVRAS-CHAVE: Educação escolar indígena. Materiais didáticos. Referencial Curricular Nacional para a Educação Escolar Indígena

\begin{abstract}
This article seeks to analyse the proposed production of books and teaching materials of the National Curricular Reference for Indigenous School Education published by the Ministry of Education in 1998. The research is developed from studies of the field of the curriculum and methodological procedures of documentary analysis. For this purpose, are analysed, especially, the lines of indigenous teachers registered in the Reference, taken as the main analysis document. The results show that the textbooks and learning materials proposed at the time favor the systematization of own/indigenous knowledge, which is one of the conditions of the indigenous school. However there is a challenge to be overcome, which is the preparation and publication of distinguished and intercultural books and teaching materials where both the indigenous knowledge and non-indigenous knowledge covered by schools are contemplated.
\end{abstract}

\footnotetext{
* Pós-doutoranda em Educação pela UCDB; Doutora em Educação pela UFMS (2012); Mestre em História pela UFGD (2006); Especialista em Educação - Metodologia do Ensino Superior, pela UFMS (2002); Especialista Ensino de Língua Portuguesa pela UNIGRAN (1994); formada em Letras habilitação Português-Inglês e demais literaturas pela UFMS (1992). Professora adjunta da FAED/UFGD. Professora colaboradora no PPGEDU/FAED/UFGD. Realiza pesquisas sobre educação escolar indígena, educação das relações étnico-raciais, currículo e formação de professores.
} 
KEYWORDS: Indigenous school education. Teaching materials. National Curricular Reference for Indigenous School Education

\section{Resumen}

Este artículo pretende analizar la producción propuesta de libros y material didáctico de la Referencia Curricular Nacional para Educación Indígena Escolar publicado por el Ministerio de Educación en 1998. La investigación se desarrolló desde los estudios de campo del currículo y procedimientos metodológicos de análisis documental. Para ello, se analizan, en particular, las líneas de los maestros indígenas registrados en la Referencia como el documento principal. Los resultados muestran que los libros de texto y materiales de aprendizaje presentados en 1998 favorecen la sistematización de conocimientos propios/indígenas, que es una de las condiciones de la escuela indígena. Sin embargo, hay un reto a superar, que es la preparación y publicación de libros y material didáctico intercultural que contengan los conocimientos indígenas y los conocimientos no indígenas.

PALABRAS CLAVE: Indígenas escuela educación. Materiales de enseñanza. Referencia Curricular Nacional para Educación Indígena Escolar

\section{INTRODUÇÃO}

As propostas de educação escolar direcionadas aos indígenas no Brasil, desde o período colonial até final dos anos 80 , estiveram marcadas por vieses colonialistas, etnocêntricos, notadamente integracionistas voltados à homogeneização cultural e linguística. Ferreira (2001) fez uma análise detalhada de um longo período histórico e defende que a história da educação escolar para os povos indígenas no Brasil pode ser "dividida" em pelo menos quatro fases: a primeira corresponderia à época do "Brasil Colônia", quando a escolarização dos índios foi realizada pelos missionários jesuítas; a segunda iniciada com a criação do Serviço de Proteção ao índio (SPI), em 1910, a qual se estendeu à política de ensino da Fundação Nacional do Índio (FUNAI), criada em 1967; a terceira foi marcada pelo surgimento de organizações indigenistas nãogovernamentais e pela formação do movimento indígena em fins da década de 1960 e nos anos 70, período da ditadura militar; "a quarta fase vem da iniciativa dos próprios povos indígenas, a partir da década de 80 , que decidem definir e autogerir os processos de educação formal" (FERREIRA, 2001, p. 72).

No que diz respeito aos diferentes grupos étnicos ou povos indígenas específicos, os processos escolares anteriores, pautados por uma ótica colonizadora, desconsideraram a autodeterminação destes povos, suas formas de organização social, suas cosmologias, suas epistemologias, suas historicidades, suas diferenças culturais e linguísticas. Sob esta orientação, as ações voltadas à educação e/ou escolarização dos colonizadores europeus, do SPI e, depois, da FUNAI objetivaram transformar os indígenas em "civilizados", cidadãos, trabalhadores nacionais através da imposição da cultura dominante/ocidental visando sua pacificação e integração à sociedade não índia (FERREIRA, 2001; TROQUEZ, 2012a).

As mudanças no sentido da construção de outro modelo de educação escolar para os indígenas surgiram no bojo de um processo amplo de mudanças no mundo, que trouxe novas demandas para a educação, as quais possibilitaram a construção de um discurso de inclusão aliado ao discurso da "escola para todos", especialmente no que diz respeito ao atendimento de grupos considerados diferenciados (COSTA; et al., 2000, 
p.1). Houve intensa mobilização no campo indigenista brasileiro, especialmente, a partir do final dos anos 1970 aos anos 1980 (TROQUEZ, 2012b). Nesta conjuntura, ganhou força o discurso do respeito à diferença, da manutenção de identidades específicas (étnicas, culturais), pautado na ideia de que a escola indígena deveria ser intercultural, comunitária, específica e diferenciada para atender os povos indígenas específicos. As discussões travadas no movimento por/sobre escolas indígenas específicas e diferenciadas incluíram a demanda por currículos e materiais didáticos também específicos e diferenciados.

As reivindicações culminaram em prerrogativas legais na Constituição Federal de 1988, as quais instituíram possibilidades de diferenciação nos processos de escolarização indígena. A partir de então, outros documentos foram elaborados no sentido da construção e da normatização de uma educação escolar indígena específica (EEI), diferenciada, intercultural e bilíngue. Entre as prerrogativas legais estava a elaboração e publicação sistemática de "material didático específico e diferenciado" (BRASIL, 1996, Art. 79).

Neste contexto, o Ministério da Educação publicou o Referencial Curricular Nacional para as Escolas Indígenas (RCNEI - BRASIL, 1998a) e a Coleção de livros didáticos do Referencial (1998b), os quais procuraram delinear uma proposta oficial para a construção de currículos e materiais didáticos específicos e diferenciados para a educação escolar indígena naquele momento histórico. O RCNEI foi elaborado por uma equipe composta de especialistas (linguistas, antropólogos, educadores) e professores indígenas. $\mathrm{O}$ referencial contém orientações referentes à elaboração de currículos e às práticas pedagógicas para todo o ensino fundamental nas escolas indígenas.

Neste artigo, apresento resultados de estudo e análise deste documento a partir de procedimentos metodológicos de pesquisa qualitativa e de análise documental, cujo objetivo principal foi investigar o que foi prescrito/proposto em 1998 para os livros e outros materiais didáticos a serem usados na escolarização indígena e suas implicações para o currículo. Para tal, foi dado especial destaque às falas dos professores indígenas que se encontram registradas no RCNEI (BRASIL, 1998a), o qual foi o principal documento curricular produzido à época. Num primeiro momento, discuto conceituações e perspectivas do estudo; a seguir apresento resultados da análise do RCNEI (1998a) com foco na sua proposta de produção de livros e/ou materiais didáticos diferenciados; e, por fim, apresento as considerações finais.

\section{Conceituações e perspectivas do estudo}

Currículo, entendido como um construto social e também político, perspectiva uma determinada visão de sociedade, de indivíduo, de educação, de cultura e de poder. Concebido como "seleção de cultura", estará sempre comprometido com a "função de transmissão cultural da escola" (FORQUIN, 1993). É considerado, nos termos de Bernstein, "um sistema de mensagem, que constitui aquilo que conta como conhecimento válido a ser transmitido" (DOMINGOS; et al., 1986, p. 346).

O currículo prescrito para a EEI pode ser concebido como produto das lutas por hegemonia entre os grupos intervenientes do campo indigenista, do campo acadêmico e do campo oficial no cruzamento com os interesses dominantes na sociedade mais ampla. Segundo Santos (2002, p. 351) "as propostas pedagógicas são frutos de debates e de disputas de diferentes naturezas. Por mais coeso que seja o grupo que elabora uma 
proposta curricular, haverá sempre conflitos e lutas de interesse na definição de um currículo".

A questão da construção de currículos específicos parece ter sido e ainda é um dos maiores desafios postos para a escolaridade dos indígenas. No que diz respeito à arena curricular, a reivindicação principal foi/é pelo reconhecimento e inclusão das culturas, línguas e identidades indígenas no currículo como elementos articuladores centrais da seleção, organização e distribuição do conhecimento, ou seja, de todo o processo de escolarização.

Segundo Troquez (2012), no cruzamento do campo indigenista com o campo acadêmico, foi se constituindo um discurso de diferenciação educacional de enfoque basicamente comunitário (voltado aos interesses de cada etnia e/ou comunidade indígena), centrado na ideia da especificidade (histórica, cultural, linguística) dos grupos envolvidos. Tal diferenciação deveria abarcar tanto a construção de escolas específicas/comunitárias em áreas indígenas com inclusão de professores índios no processo escolar quanto a construção de currículos e materiais didáticos específicos. Este entendimento reporta à ideia de um currículo local determinado pela cultura e língua locais, mesmo que incorpore conhecimentos universalmente construídos.

Contudo, no que diz respeito à sociologia do conhecimento escolar, a perspectiva dominante reivindica um currículo de inspiração universalista (FORQUIN, 1993) em que os estudantes de uma mesma faixa etária tenham oportunidades iguais de acesso e sucesso perante conhecimentos considerados "válidos" ou "poderosos" (YOUNG, 2007, p. 1293), como garantia de qualidade e de igualdade perante o conhecimento. Young, ao reconhecer o papel primordial da escola como "agente de transmissão cultural", tece a seguinte argumentação:

\begin{abstract}
Sendo aceito que as escolas têm esse papel, fica implícito que os tipos de conhecimentos são diferenciados. Em outras palavras, para fins educacionais, alguns tipos de conhecimentos são mais valiosos que outros, e as diferenças formam a base para a diferenciação entre conhecimento curricular ou escolar e conhecimento não-escolar. Existe algo no conhecimento escolar ou curricular que possibilita a aquisição de alguns tipos de conhecimentos. Portanto, minha resposta à pergunta 'para que servem as escolas?' é que elas capacitam ou podem capacitar jovens a adquirir o conhecimento que, para a maioria deles, não pode ser adquirido em casa ou em sua comunidade, e para adultos, em seus locais de trabalho. (2007, p. 1293).
\end{abstract}

Na sua defesa do conhecimento escolar como um conhecimento especializado, Young ancora-se nas conceituações de Bernstein sobre a diferenciação do conhecimento. Segundo Bernstein (1998, p. 196), o conhecimento especializado, a ser adquirido na escola, corresponde ao conhecimento vertical ou teórico (acadêmico), "com formas essencialmente escritas", independente de contexto e diferencia-se do conhecimento horizontal, de tradição oral, de base local, adquirido no cotidiano. Sob esta perspectiva, a escola é vista como uma instituição de transmissão cultural cujo currículo deve garantir o acesso ao conhecimento "especializado", do tipo escolar ou acadêmico, o conhecimento "poderoso". Pois este, necessário para o "progresso" do indivíduo na sociedade atual (GIMENO SACRISTAN, 2002), dificilmente será adquirido no espaço do cotidiano. A defesa a favor dos conhecimentos escolares "especializados" é dominante na teoria crítica de currículo, sobretudo, nos estudos que tomam por base a sociologia do conhecimento escolar de Forquin (1993). 
Esta perspectiva foi/é tensionada pelas reivindicações por currículos locais e diferenciados que consideram válidas e legítimas as diferentes epistemologias e os diferentes conhecimentos produzidos por povos de outras tradições culturais. CastroGómez, ao discorrer sobre "ciências sociais, violência epistêmica e o problema da 'invenção do outro"' (CASTRO-GÓMEZ, 2005, p.86), discute a necessidade de repensar a teoria crítica e aponta para o desafio latino-americano de 'descolonização' das ciências sociais. A construção de currículos diferenciados, pautados pelo princípio da interculturalidade impõe-nos esta necessidade e o enfrentamento deste desafio.

A legislação educacional brasileira, ao mesmo tempo em que trouxe avanços no sentido do respeito à diferença e do direito à educação diferenciada, institui a obrigatoriedade de uma base nacional comum para o currículo. Esta premissa encontrase no artigo 210 da Constituição Federal de 1988.

\footnotetext{
Art. 210. Serão fixados conteúdos mínimos para o ensino fundamental, de maneira a assegurar formação básica comum e respeito aos valores culturais e artísticos, nacionais e regionais.

[...]

$\$ \mathbf{2}^{\mathbf{0}} \mathrm{O}$ ensino fundamental regular será ministrado em língua portuguesa, assegurada às comunidades indígenas também a utilização de suas línguas maternas e processos próprios de aprendizagem.
}

Na mesma direção, o Artigo 26 da Lei de Diretrizes e Bases da Educação Nacional de 1996 reforça a necessidade de uma "base nacional comum" para o currículo da educação básica e o Artigo $32 \S 3^{\circ}$ mantém a garantia da Constituição quanto ao uso de suas línguas maternas e processos próprios de aprendizagem. No contexto legal e normativo, o currículo da EEI precisa se equilibrar entre a diferença (os conteúdos locais/próprios) e a igualdade (a base nacional comum); ou entre o que lhe é próprio, o local e o que vem de fora, os conteúdos escolares ou especializados.

$\mathrm{Na}$ tentativa de propor uma alternativa ao impasse sobre as discussões em torno da escola diferenciada para indígenas, no que diz respeito a questões relacionadas ao seu vínculo com a exterioridade e às questões endógenas, o que inclui a questão curricular, Tassinari argumenta que

[...] não é possível definir a escola como uma instituição totalmente alheia. Por outro lado, também não se pode compreendê-la como completamente inserida na cultura e no modo de vida indígena. Ela é como uma porta aberta para outras tradições de conhecimentos, por onde entram novidades que são usadas e compreendidas de formas variadas. (2001, p. 50).

A partir das considerações de Tassinari, podemos pensar os currículos das escolas indígenas como constituídos num espaço fronteiriço. Parafraseando-a dizemos que o currículo da escola indígena é como uma porta aberta para outras tradições de conhecimentos. Não é concebido como um artefato totalmente alheio à realidade indígena, mas, por outro lado, também não é constituído somente de conteúdos locais ou próprios, pois é pautado pelo princípio da interculturalidade. Sob esta perspectiva, garante-se espaço no currículo para conhecimentos escolares/especializados, sem desconsiderar a legitimidade e a centralidade dos conhecimentos locais. Este currículo pode/deve ser construído localmente, devidamente contextualizado, a partir de conteúdos culturais próprios e ser realizado por professores indígenas, nas línguas maternas indígenas, trabalhado a partir de pedagogias diferenciadas e por processos 
educacionais próprios de cada grupo ou povo, como garantia do direito à diferença e do respeito à diversidade.

A escola é considerada pelos indígenas como um forte instrumento de sobrevivência e luta frente à sociedade não-índia, pois os conhecimentos adquiridos via escolarização podem ajudá-los nas lutas do cotidiano, desde o fato de não serem enganados no mercado ao entendimento correto das leis que lhes dizem respeito (BENITES, 2003). Embora houve/há a força das reivindicações por uma escolarização "voltada para dentro", para a preservação e reprodução dos conteúdos culturais próprios, dialeticamente pode-se perceber a necessidade de uma escolarização (consubstanciada nos conhecimentos escolares/especializados, universais/letrados que ela representa) que prepare os índios para conviver no atual contexto.

A seguir apresento resultados da análise do Referencial Curricular Nacional para as Escolas Indígenas (BRASIL, 1998a) com foco na sua proposta de diferenciação no que concerne à proposta de produção de livros e de outros materiais didáticos diferenciados.

\section{Tentativas/propostas de diferenciação: os livros/materiais didáticos}

Gimeno Sacristán (1998, p. 150), afirma que, de forma predominante, os livros didáticos ou "livros-texto" é que estruturam a prática escolar. Desta forma, são "o apoio imediato dos professores para tomar decisões quanto à programação de seu ensino", pois estruturam o currículo, desenvolvem seus conteúdos e apresentam-nos aos professores em termos de estratégias de ensino.

De acordo com Cortesão e Stoer (2003), em determinadas situações pedagógicas, é através dos materiais didáticos que se faz a recontextualização pedagógica do saber.

\footnotetext{
Assim sendo, a grande tarefa de 'tradução', essencialmente, é realizada a nível da elaboração de materiais didáticos. Estes procuram combinar uma recontextualização dos saberes científicos contemplados pelos conteúdos programáticos, aqueles saberes que foram considerados importantes para serem transmitidos e, simultaneamente, fazem uma interpretação de finalidades, e de metodologias, que constam do projeto curricular, tendo também em atenção os ritmos de aprendizagem que se esperam 'normalmente' dos alunos. (CORTESÃO; STOER, 2003, p. 200).
}

Para os autores, os materiais didáticos são produzidos para um grupo de alunos, considerados "normais", ou seja, há uma ideia de uniformização ou homogeneização dos estudantes implícita na distribuição nacional de livros didáticos. Por outro lado, alguns estudos denunciam o viés homogeneizante, ideológico e reprodutor de estereótipos que predominaram e ainda predominam nos livros didáticos nacionais (MANCINI; TROQUEZ, 2009; BERGAMASCHI; GOMES, 2012; RUSSO; PALADINO, 2016).

As orientações pedagógicas e os relatos de professores indígenas presentes no Referencial Curricular Nacional para as Escolas Indígenas (RCNEI - BRASIL, 1998a) denunciaram a utilização de livros didáticos nacionais nas escolas indígenas e explicitaram a necessidade da construção de materiais diferenciados. Em contraposição ao viés homogeneizador dos livros didáticos nacionais, o discurso em defesa da diferenciação reclamou pela necessidade da produção de livros e outros materiais 
didáticos específicos, de acordo com as realidades indígenas, pois a falta de material específico figurava entre os principais entraves para a efetivação da escola diferenciada.

As dificuldades que vivemos para construir esta escola diferenciada é que não temos livros diferentes. Os que temos são iguais aos da cidade e não falam de nossos povos indígenas.... Este problema pode ser superado através da produção de livros nossos.... Em cursos de formação e capacitação. Maria José Lima, Professora Xucuru, PE. (BRASIL, 1998a, p. 80).

No que diz respeito aos conteúdos de ensino, pela análise operada no RCNEI (BRASIL, 1998a) identificamos a recorrência de, pelo menos, quatro grupos de conteúdos admitidos para a escola diferenciada: a) os conhecimentos denominados próprios ou locais; b) os conhecimentos acadêmicos oriundos das disciplinas escolares (disciplinares); c) os temas transversais definidos para as escolas indígenas; e d) os conhecimentos de outros grupos ou povos.

O discurso de diferenciação, voltado à construção de livros e outros materiais didáticos específicos, evidenciou o privilégio dado aos conhecimentos locais a serem sistematizados e veiculados nas escolas indígenas.

\footnotetext{
O professor, junto com seus alunos, pode elaborar textos, fotografias, desenhos, vídeos etc., sobre sua cultura corporal, a serem aproveitados de diferentes maneiras: como material didático na própria escola; como material de divulgação da cultura indígena para a sociedade envolvente; ou como objeto de troca com outras comunidades indígenas que venham a produzir algo semelhante. (BRASIL, 1998a, p. 326).
}

Uma questão importante a destacar é a intencionalidade presente nas orientações do RCNEI de que os textos e outros materiais produzidos pelos alunos e professores indígenas pudessem ser usados também em escolas não indígenas, como forma de divulgação dos conhecimentos, histórias e culturas indígenas numa perspectiva de educação intercultural. Dez anos depois da elaboração do RCNEI, foi instituída a LEI 11.645/2008 que obriga o ensino das histórias e culturas indígenas nas escolas de educação básica de todo país.

Os relatos dos professores indígenas deram a tônica do que deveria ser registrado nos livros didáticos diferenciados. Um aspecto muito enfatizado foi a necessidade de registro de aspectos históricos e culturais para serem ensinados às novas gerações, como verificamos no relato abaixo:

O que eu tenho dificuldade é para me esclarecer mais e desenvolver o trabalho da minha história. Para passar dentro da minha escola indígena, para meus filhos que estão presentes dentro da área indígena.

E inclusive elaborar uma cartilha para nós ensinarmos nossos filhos e os nossos netos que estão nascendo daqui para frente. Por isso, eu estou interessado em pesquisar a minha história, música de mariri, cipó, pescaria, caçada, sonho, batismo, gavião etc. E para registrar no cartório para não se acabar mais. Como era a história de antigamente e a história do passado. Ex: o conhecimento do nosso avô, de 1940, como nossos parentes eram no tempo de cativeiro. Neste ano eu vou pesquisar nos outros lugares onde nossos parentes estão morando no Peru.

Eu, professor, penso no futuro em construir mais material didático dentro de área indígena para nossos alunos aprenderem. Paulo Siã, professor Kaxinawá, AC. (BRASIL, 1998a, p. 82). 
No relato a seguir, privilegiou-se a pesquisa da história, do passado, e o estabelecimento de comparações com o presente no sentido de registrar também as transformações socioculturais:

Vamos junto com os outros professores pesquisar, neste ano de 1998, um pouco da nossa história cultural, a dos Asheninka.

- como eram feitas as festas antigamente

- qual era o nome

- as músicas

- se tinha uma data certa para essa festa, se ainda são as mesmas de hoje ou se já mudou bastante

- que tipos de brinquedos eram utilizados para as crianças brincarem. $O$ nome se o homem brincava e se as meninas também brincavam saber se era do próprio povo ou foi emprestado de outros quais são os de hoje e se teve muita mudança ou não.

Registrar tudo isso para servir de material para trabalhar na escola. E vamos trazer alguns materiais para o próximo ano, no próximo curso. Se realizarmos outra pesquisa também vamos trazer para mostrar. Isaac. S Pinhanta, Valdete S. Pinhanta Komâyari, professores Asheninka, AC. (BRASIL, 1998a, p. 82).

Outro professor enfatizou o registro de letras de "cantorias" dos mais velhos na composição de cartilhas:

No próximo ano vou fazer os velhos cantar nossas cantorias. Eu vou gravar no gravador para trazer a fita gravada aqui no curso, para fazer as cartilhas. Lá na minha escola ainda não tem cartilhas feitas para professor $e$ alunos. Então, eu vou trazer esta fita gravada no gravador e outras mais etc. Miguel Alves, professor Kaxarari, RO. (P. 83).

Conforme orientações do RCNEI, a construção de materiais didáticos deveria ser realizada a partir de pesquisas nas comunidades, especialmente junto aos mais velhos, considerados detentores dos saberes e histórias tradicionais dos grupos, e de experiências vividas em sala de aula "em diálogo" com as disciplinas escolares. O espaço privilegiado para a construção dos materiais específicos deveria ser os cursos de formação de professores indígenas.

Reunidos nos cursos de formação, professores vêm organizando projetos de pesquisas, oficinas de produção de temas como vídeos e livros com temáticas específicas. E assim está sendo produzida uma variedade de materiais importantes ligados à cartografia (como mapas diversos), à reflexão sobre o meio ambiente (com pesquisas de espécies da fauna flora) às narrativas históricas e míticas, às músicas e outras partes de sua tradição oral etc. (BRASIL, 1998a, p. 69).

Na ocasião da publicação do RCNEI, o MEC financiou a publicação da "Coleção de Livros Didáticos do Referencial Curricular Nacional para as Escolas Indígenas" (BRASIL, 1998b), elaborados a partir das experiências acima mencionadas. A coleção foi distribuída nas escolas indígenas juntamente com cópias do RCNEI. Trata-se de

[...] coleção de livros elaborados por professores de diferentes etnias, pretendendo oferecer referências, exemplificando como é possível a construção de material didático de qualidade adequado a cada comunidade 
indígena, e ao mesmo tempo, iniciar um intercâmbio entre os diferentes povos e escolas indígenas do país. (BRASIL, 1998b, p. 07).

Os livros publicados são: Geografia indígena (1996); O Livro das Árvores (1998); Xanetawa Parageta - Histórias das Nossas Aldeias (1996); Yama Ki Hwërimamouwi thë ã oni - Palavras escritas para nos curar (1977); Pangyjej Kue Sep A nossa língua escrita no papel (1994); Adornos e Pintura Corporal Karajá (1998); Atlas Geográfico Indígena do Acre (1996); Aprendendo Português nas Escolas da Floresta (1997); Txopai e Itôhã (1997); O tempo passa e a história fica (1997); "Madikauku - os dedos das mãos": Matemática e Povos Indígenas no Brasil (1998) ${ }^{1}$.

De modo geral, estas publicações dizem respeito, entre outros, a aspectos da história, da língua e da dinâmica cultural local. Ou seja, foram produzidos a partir de conhecimentos locais. O RCNEI destaca o "Livro das árvores" como exemplo:

O 'Livro das Árvores', de autoria dos Tikuna (AM), é um exemplo de como, ao se dar atenção a um tema socialmente importante como a terra e a biodiversidade, as disciplinas escolares de Ciências, Geografia, Línguas, História, Arte e ainda outras podem estar integradas num processo de contínua construção de novos e velhos conhecimentos nas escolas indígenas. (BRASIL, 1998a, p. 69).

Figura 1. O Livro das árvores

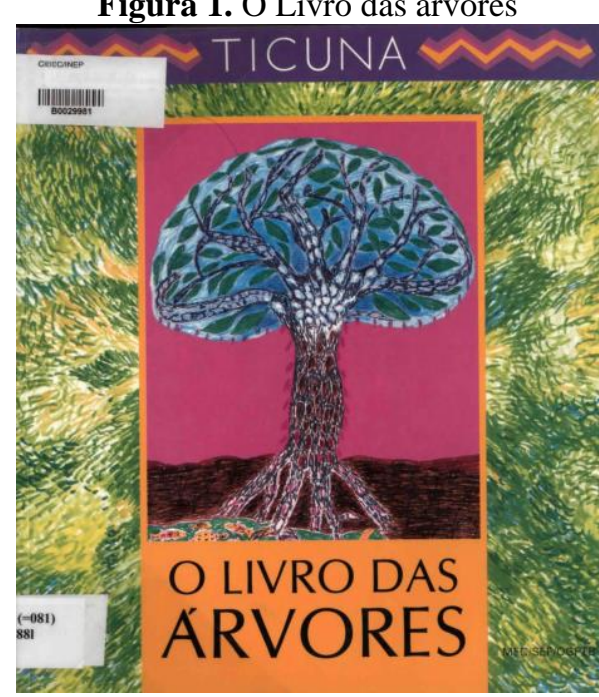

Fonte: Gruber, 1997, capa.

O livro citado acima ilustra, de um lado, o privilégio dado aos conteúdos locais/próprios, pois é uma publicação elaborada por professores indígenas com o objetivo de registrar aspectos históricos, conhecimentos práticos, valores simbólicos e inspiração poética no que concerne à "natureza segundo os Ticuna". De outro, sistematiza o resultado de um levantamento de dados e da elaboração de desenhos sobre a flora e a fauna regionais, apresentando "a intensa e rica relação dos Ticuna com as árvores que formam a floresta, focalizando o valor e o significado de várias espécies, preferencialmente nativas, para a sua sobrevivência física e cultural" (GRUBER, 1997, p. 07). Desta forma,

\footnotetext{
${ }^{1}$ Cópias virtuais destes materiais estão disponíveis no site $\underline{\text { www.dominiopublico.gov.br. }}$
} 
Não se trata de um livro de botânica, mas de uma memória das árvores, que permite aos Ticuna recordar a importância de cada uma delas na sua vida. Folheando página por página, compreende-se as razões que os levam à defesa e preservação de suas florestas, um patrimônio que deverá ser eterno, passando de pai para filho, como uma herança das mais belas e mais ricas.

O livro acolhe o olhar dos Ticuna sobre a natureza que os cerca e lhes serve de morada, trazendo textos e imagens que fixam suas concepções do real e do imaginário, numa linguagem onde se entremeiam conhecimentos práticos, valores simbólicos e inspiração poética.

O Livro das árvores é uma obra de arte que encanta devido a seus desenhos de cores vivas recheados de significados e emoldurados por textos de autoria Tikuna que narram aspectos da vida deste povo e, assim, registram conhecimentos da memória coletiva.

Figura 2. A samaumeira que escurecia o mundo

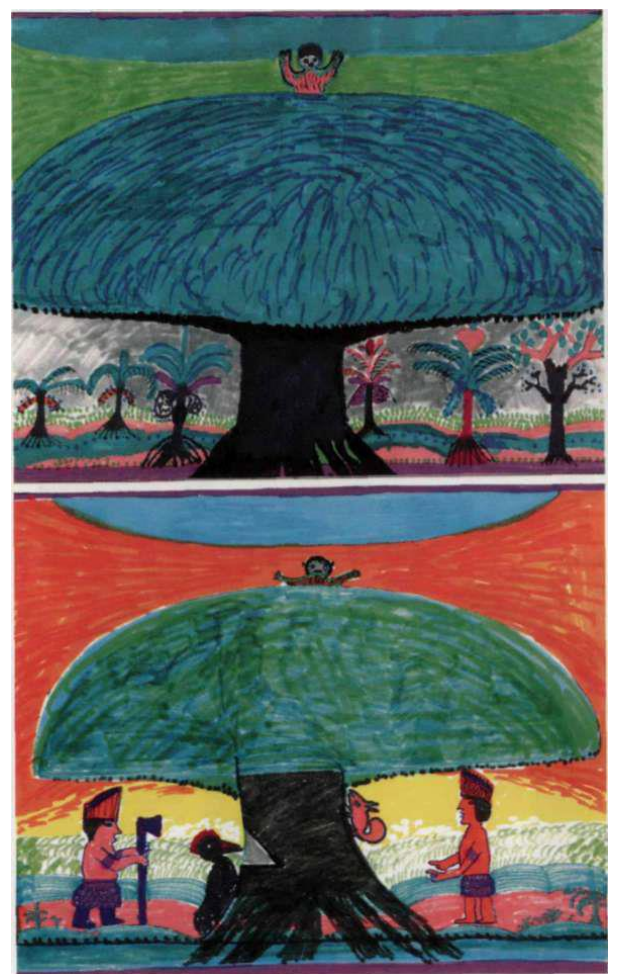

Fonte: Gruber, 1997, p. 12.

Cabe destacar que os desenhos apresentados, com exceção de dois, foram elaborados individualmente, ao passo que os textos são resultado de uma produção coletiva, baseados em um saber de domínio também coletivo.

Este livro é dedicado principalmente às crianças e adolescentes, alunos das escolas Ticuna. Mas seria importante que também fosse lido pelas crianças não-índias das tantas escolas do país. Elas poderiam conhecer os Ticuna, contemplar seus desenhos e aprender sobre a floresta amazônica através da palavra de seus habitantes mais antigos. (GRUBER, 1997, p. 07).

Trata-se da sistematização de conhecimentos locais que podem ser utilizados como material escolar nas escolas indígenas e, ainda contribuir para o conhecimento a respeito das sociedades indígenas do Brasil nas escolas não indígenas. Não raro, 
determinados conhecimentos (medicinais, biológicos, botânicos, de manejo ambiental) produzidos e reproduzidos pelas comunidades indígenas têm sido apropriados, de forma indevida, por pesquisadores, empresários, entre outros. A sistematização e o registro de conhecimentos próprios ou tradicionais têm sido discutidos e defendidos por muitos pesquisadores, bem como a proteção à propriedade intelectual destes conhecimentos indígenas coletivos ou individuais (CUNHA, 2007). Neste sentido, a escolarização tem sido reclamada a dar sua contribuição.

Embora a elaboração de materiais didáticos específicos que contemple, entre outros aspectos, a sistematização de saberes próprios seja considerada uma das condições da escola indígena, cerca de 20 anos depois da publicação do RCNEI (1998a) e 30 anos depois da Constituição Federal de 1988, este continua a ser um grande desafio a enfrentar tanto no campo das políticas públicas, quanto das práticas escolares.

Se, por um lado, os livros didáticos que chegam às escolas do país, estabelecidos pelo Programa Nacional do Livro Didático (PNLD) e que são usados nas escolas indígenas, podem ser considerados veículos portadores de preconceitos, de lógicas e ideologias dominantes; por outro lado, a construção de material diferenciado nos moldes exemplificados pela coleção dos livros didáticos do RCNEI (1998) suprem uma lacuna importante, que é a produção de material didático com foco nas epistemologias e nos conhecimentos tradicionais locais, voltados aos grupos étnicos específicos. Contudo, fica uma grande lacuna a ser preenchida que é a construção de materiais didáticos diferenciados e específicos constituídos dos outros conteúdos escolares ditos "especializados", constituintes do currículo e considerados importantes que os alunos aprendam. Na verdade, o grande desafio é a construção de materiais diferenciados interculturais em que conhecimentos indígenas e não indígenas sejam contemplados "para todas as áreas do conhecimento" (BRASIL, 2012, Art. $7^{\circ} \S 4^{\circ}$ ).

Cumpre destacar que, a elaboração e publicação sistemática de material didático específico e diferenciado já vem sendo pontuada desde a LDBEN (BRASIL, 1996) e foi reforçada pelas Diretrizes Curriculares Nacionais para a Educação Escolar Indígena na Educação Básica (BRASIL, 2012). E desde 2013 (quinze anos depois da publicação do RCNEI), está em andamento em diversas áreas indígenas do país a Ação Saberes Indígenas na Escola, regulamentada pela Portaria $N^{\circ}$ 98, de 06/12/2013, do Ministério da Educação, em regime de colaboração com os estados, o Distrito Federal, os municípios e as instituições de ensino superior. A ação integra o Eixo Pedagogias Diferenciadas e o Uso das Línguas Indígenas do Programa Nacional dos Territórios Etnoeducacionais Indígenas. Está entre os objetivos da ação: "fomentar pesquisas que resultem na elaboração de materiais didáticos e paradidáticos em diversas linguagens, bilíngues e monolíngues, conforme a situação sociolinguística e de acordo com as especificidades da educação escolar indígena” (BRASIL, 2013, Art 2º Inciso IV). Os materiais produzidos a partir da Ação Saberes Indígenas não foram objeto de análise para este artigo.

\section{CONSIDERAÇÕES FINAIS}

A educação escolar indígena no Brasil foi construída num longo processo histórico pautada por diferentes políticas orientadas pelos diferentes atores que estiveram atuando em cada momento de sua história. Desde seus primórdios, esteve marcada por ideais civilizatórios e colonizadores. 
Com a Constituição Federal de 1988, foi instaurada uma ruptura legal e epistemológica em relação aos períodos anteriores. Houve muitos avanços no que diz respeito à construção da educação escolar diferenciada para indígenas no Brasil. Sobretudo, não pode ser ignorada a autonomia e a participação dos professores indígenas na elaboração do Referencial Curricular (BRASIL, 1998a), a possibilidade da construção de currículos diferenciados, de livros e outros materiais didáticos específicos com a inclusão de conteúdos históricos e conteúdos culturais próprios para serem ensinados às novas gerações.

No que que diz respeito aos conhecimentos escolares/especializados, cumpre destacar que permanece um grande desafio aos professores índios e aos profissionais que atuam em processos de formação de professores: elaborar e oferecer/distribuir livros e materiais didáticos específicos/diferenciados aos indígenas que garantam o acesso adequado/contextualizado dos conhecimentos escolares/especializados.

Neste sentido, os modos próprios de transmissão e de aprendizagem, os conhecimentos locais, as experiências cotidianas, as histórias de família e outros aspectos ligados à vida diária dos alunos, são reclamados no sentido de valorização dos alunos, de suas origens (culturais, étnicas...) e, ainda, podem se constituírem como "recurso" para a aquisição dos conhecimentos especializados a serem transmitidos pela escola. Ou seja, há que se construir livros e materiais didáticos diferenciados mais adequados à realidade de cada povo ou grupo étnico. Cumpre destacar a importância de "valorizar os conhecimentos indígenas, não só como conhecimentos locais, mas, também como conhecimentos válidos para compor os chamados conhecimentos universais" (NASCIMENTO, 2018).

Ao adotar esta perspectiva, pode-se aliar a existência de conteúdos curriculares comuns às diferenças locais dos grupos indígenas envolvidos a partir da construção e/ou recriação de dispositivos pedagógicos específicos para cada realidade. A partir de uma perspectiva intercultural e de práticas pedagógicas diferenciadoras, podem-se construir livros e outros materiais didáticos que valorizem os conteúdos culturais próprios sem privar os alunos indígenas do acesso a outros conhecimentos escolares/especializados.

Neste caso, há que termos sempre em mente os processos de colonização e subalternização a que foram submetidas as culturas indígenas e que, de algum modo, ainda se fazem presentes nas suas escolas. E estas, como portas abertas para outras possibilidades vão construindo suas próprias histórias, seus currículos e suas práticas.

\section{REFERÊNCIAS}

BENITES, Tonico. Mbo'e Kátia ñemoñe'ê há japo kuatia ñe'ê: (Fazendo o papel falar e produzindo sua fala). 2003. Monografia (Graduação Normal Superior) - Universidade Estadual do Mato Grosso do Sul, 2003.

BERNSTEIN, Basil. Pedagogia, control simbólico e identidad. Madrid: Morata, 1998.

BERGAMASCHI, Maria Aparecida; GOMES, Luana Barth. A temática indígena na escola: ensaios de educação intercultural. Currículo sem Fronteiras, v.12, n.1, pp. 5369, Jan/Abr. 2012. 
BRASIL. Ministério da Educação e do Desporto. Secretaria de Educação Fundamental. Referencial Curricular Nacional para as Escolas Indígenas. Brasília, DF: MEC/SEF, 1998a.

. Ministério da Educação e do Desporto. Secretaria de Educação Fundamental. Coleção de livros didáticos do Referencial Curricular Nacional para as Escolas Indigenas: informações para o professor. Brasília, DF: MEC/SEF, $1998 \mathrm{~b}$.

- Ministério da Educação. Conselho Nacional de Educação. Câmara de Educação Básica. Resolução $N^{o} 5$, de 17 de dezembro de 2009. Define Diretrizes Curriculares Nacionais para a Educação Escolar Indígena na Educação Básica, 2012.

CASTRO-GÓMEZ, Santiago. Ciências Sociais, violência epistêmica e o problema da "invenção do outro". In: LANDER, Edgardo. (Ed.). A colonialidade do saber: eurocentrismo e ciências sociais. Perspectivas latino-americanas. Buenos Aires: CLACSO, 2005. p. 80-87.

CORTESÃO, Luiza; STOER, Sthephen R. A interface da educação intercultural e a gestão da diversidade na sala de aula. IN: GARCIA, Regina Leite; MOREIRA, Antônio Flávio. Currículo na contemporaneidade. São Paulo: Cortez, 2003, p. 189-208.

COSTA, Ana M. Bénard da; et al. Diferenciação Curricular e Inclusão. In: Currículos Funcionais - Manual para Formação de Docentes. Instituto de Inovação Educacional do Ministério da Educação, 2000.

CUNHA, Manuela Carneiro da (Org.). Relações e dissensões entre saberes tradicionais e saber científico. Revista USP, São Paulo, n. 75, p. 76-84, set./nov. 2007.

DOMINGOS, Ana Maria; et al. A teoria de Bernstein em sociologia da educação. Portugal: Fundação Calouste Gulbenkian, 1986.

FORQUIN, Jean-Claude. Escola e cultura: a sociologia do conhecimento escolar. Porto Alegre: Artes Médicas, 1993.

FERREIRA, Mariana Kawall Leal. A educação escolar indígena: um diagnóstico crítico da situação no Brasil. In: SILVA, A. L.; FERREIRA, M. K. L. F. (Orgs.). Antropologia, História e Educação: a questão indígena na escola. São Paulo: Global, 2001, p. 71- 111.

GIMENO SACRISTÁN, J. O currículo: uma reflexão sobre a prática. Porto Alegre: Artmed, 1998.

Educar e conviver na cultura global: as exigências da cidadania. Porto Alegre: Artmed, 2002.

GRIGNON, Claude. Cultura dominante, cultura escolar e multiculturalismo popular. In: SILVA, Tomaz, Tadeu da (Org.). Alienígenas na sala de aula. 6 ed. Petrópolis: Vozes, 2005, p. 178-189. 
GRUBER, Jussara Gomes (Org.). O livro das árvores. Benjamim Constant: Organização Geral dos Professores Ticuna Bilíngues, Impressão: Gráfica e Editora Brasil Ltda., 1997. Disponível em:

<http://www.dominiopublico.gov.br/download/texto/me002040.pdf >. Acesso em: 26.02.2019.

MANCINI, Ana Paula Gomes; TROQUEZ, Marta Coelho Castro. Desconstruindo estereótipos: apontamentos em prol de uma prática educativa comprometida eticamente com a temática indígena. Revista Tellus, Campo Grande, UCDB, ano 9, n. 16, p.181208, jan./jun. 2009.

NASCIMENTO, Adir Casaro. Palestra. Faculdade de Ciências Humanas/UFGD: Dourados, MS, 27 de agosto de 2018.

RUSSO, Kelly; PALADINO, Mariana. Alei n. 11.645 e a visão dos professores do Rio de Janeiro sobre a temática indígena na escola. Revista Brasileira de Educação, v. $21 \mathrm{n}$. 67 out./dez. 2016

SANTOS, Lucíola Licínio de C. P. Políticas públicas para o ensino fundamental: Parâmetros Curriculares Nacionais e Sistema Nacional de Avaliação (SAEB). Educação \& Sociedade, Campinas, vol.23, n.80, p. 346-367, set. 2002.

SAVIANI, Dermeval. Escola e democracia. Edição comemorativa. Campinas: Autores Associados, 2008.

SOARES, Magda. Linguagem e escola: uma perspectiva social. São Paulo: Ed. Ática, 1987.

TROQUEZ, Marta Coelho Castro. Documentos curriculares para a educação escolar indígena: da prescrição às possibilidades da diferenciação. 2012a. 258f. Tese (Doutorado em Educação) - UFMS, Campo Grande.

. Notas sobre a emergência do direito à educação diferenciada para indígenas no contexto mundial (1948-2007). Revista Monções, v.1, n.1, jan./jun. 2012 b.

YOUNG, Michael. Pra que servem as escolas? Educação \& Sociedade, Campinas, v. 28, n. 101, p. 1287-1302, set./dez. 2007.

Recebido em: 09/12/2018

Aprovado em: 06/01/2019 